\title{
Quantification of valvular regurgitation by cardiac blood pool scintigraphy: correlation with catheterization
}

\author{
J-P. Melchior ${ }^{*} \dagger$, M. Chevigne*, A. Righetti $\dagger$, B. de Bruyne*, J-P. Salembier *, J-C. Barthelemy ${ }^{*}$, \\ B. MARChANDISE* \\ * Cardiology Department, University of Louvain, Mont-Godinne, Yvoir, Belgium and † Cardiology Center, \\ University Hospital, Geneva, Switzerland
}

KEY WORDS: Valvular regurgitation, regurgitant fraction, cardiac catheterization, radionuclide ventriculography.

The diagnosis of valvular regurgitation $(R)$ is usually based on clinical signs. Quantification conventionally requires catheterization $(C)$. We have quantified $R$ with cardiac blood pool scintigraphy $(C B P S)$ and compared the results with those obtained by $C$. Regurgitant fraction $(R F)$ determined by $C$ was calculated with the technique of Dodge. Forward output was measured by thermodilution or cardiogreen dilution. The $R F$ at $C B P S$ was obtained by the stroke index ratio $(S I R)$ minus $I \cdot 2$ divided by SIR, where SIR is the ratio of the stroke counts of left venticle over those of the right ventricle. Stroke counts are calculated directly from the timeactivity curves. Each time-activity curve was obtained by drawing one region of interest around each diastolic image. The correction factor $(1 \cdot 2)$ was calculated from a large normal population. 22 patients had aortic $R, 7$ mitral $R, 12$ both, 8 patients had no evidence of regurgitation. $R F$ of the patients with $R$ varied from 27 to $71 \%$ $(\bar{x}=42 \%)$ at $C$ and from 26 to $74 \%(\bar{y}=41 \%)$ at CBPS. Linear regression shows a good correlation coefficient $(r=0.82)$. The regression equation is $y=0.93 x+1.8$. No correlation was found between $R F(C B P S$ or $C)$ and the severity of $R$ assessed visually from angiography. In conclusion: CBPS, a non-invasive method, allows easy and repeatable determination of $R F$ and correlates well with data obtained at catheterization.

\section{Introduction}

The diagnosis of aortic or mitral valve regurgitation is usually based on clinical signs. The severity of valvular regurgitation is conventionally assessed by angiography: semiquantitative visual evaluation ${ }^{[1-2]}$ or quantitation by combined left ventriculography and forward output determination ${ }^{[3]}$. It is often difficult to decide on the optimal time of operative repair and repeated invasive procedures are sometimes necessary ${ }^{[4]}$.

In 1979, Rigo et al ${ }^{[5]}$ introduced a new quantitative technique for evaluation of regurgitation using cardiac blood pool scintigraphy (CBPS). CBPS is a safe, non-invasive, repeatable method of evaluating left and nght ventricular function. The regurgitant fraction is calculated from the ratio of the stroke counts of the two ventricles.

The aim of the present study is to investigate valvular regurgitation using the CBPS technique and to compare the results with those obtained invasively by classical catheterization.

Address for correspondence: J-P. Metchior, Service de Cardiologie, Clinique Ste Elizabeth, Avenue Defré, 206, B-1180 Bruxelles. Belgium.

\section{Methods}

PATIENTS

Ninety-one patients who underwent left and right catheterization were considered for our study, 42 were excluded because of: atrial fibrillation during the procedure (3), premature beats during left ventriculography (11), tricuspid regurgitation (clinical and/or Doppler evidence) (5), regional motion abnormalities (old myocardial infarct) (10) and non-reproducible values of the cardiac output (13).

The remaining 49 patients ( 18 females, 31 males, mean age 54 years: range $21-74$ ) were evaluated by CBPS within $48 \mathrm{~h}$ of catheterization without any intervening change of therapy. They comprised 8 control patients with no clinical or angrographic evidence of regurgitation and 41 patients with a left regurgitation: 22 aortic, 7 mitral and 12 both.

\section{CATHETERIZATTON}

The angiographic method included RAO $30^{\circ}$ (37 patients) or biplane (RAO $\left.30^{\circ}-\mathrm{LAO} 60^{\circ}\right)(12$ patients) left ventriculography with a pig-tail catheter in mild inspiration using a power injection of 40-50 ml contrast at $12-15 \mathrm{ml} \mathrm{s}^{-1}$. A grid or a $6 \mathrm{~mm}$ ball 
filmed at the level of the patient's heart was used to correct for $\mathrm{X}$-ray magnification. The end-diastolic endocardial contour was traced using the frame at the onset of QRS. The end-systolic contour was drawn from the frame at which the left ventricular volume reached a mınımum by visual evaluatıon. Sequential numbers were allocated to each frame, so that the same cardiac cycle and simultaneous frames were selected for biplane analysis. Angiographic stroke volume was calculated with the method of Sandler et $\mathrm{al}^{[3]}$ using the correction factor of Kennedy et $a l^{[6]}$ only for the simple plane ventriculographies. Forward output was determined using one of two dilution techniques: etther iced saline with a Swan-Ganz catheter in the main pulmonary artcry, or cardiogreen with the dye injected in the pulmonary artery and collected in the proximal descending aorta. Thermodilution curves (46 patients) were obtaned in triplicate before angio and a mean value was derived, and a fourth curve was obtained simultaneously with the contrast injection. Cardiogreen (16 patients) was injected twice just before angıgraphy. Thirteen patients were excluded because of the difference between the cardiac output values (greater than $10 \%$ difference). In order to calculate the regurgitant fraction, we used the forward output value obtained by thermodilution during ventriculography or the mean value of the two results calculated from the cardiogreen dilution curves

The regurgitant fraction was calculated as:

$$
\begin{aligned}
& \mathrm{RF} \%= \\
& \text { Angiographic output - Forward output }
\end{aligned}
$$$$
\text { Angiographic output }
$$
$\times 100$

\section{CARDIAC BLOOD POOL SCINTIGRAPHY}

Red cells labelling was performed by an in wvo technique with preinjection of stannous fluonde followed $20 \mathrm{~min}$ later by $25 \mathrm{mCi}$ of technetium pertechnetate. An initial delay of $15 \mathrm{~min}$ after injection was respected before the first scintigraphic measurement, to allow for equilibrium of tracer in the blood pool.

The camera was positioned at a $35-45^{\circ}$ LAO angle with a $0-10^{\circ}$ craniocaudal obliquity. The chosen incidence was the one allowing the best visual separation of the four cardiac chambers. The $R$ wave of the electrocardiogram was used as the synchronizing signal and the $\mathrm{R}-\mathrm{R}$ interval was divided in 16 images using a $64 \times 64$ matrix.

Left and right ventricular regions of interest were traced on simultaneous displayed images of diastole, and systole and on phase and amplitude Fourier images. Both time-activity curves were directly obtained from those two diastolic regions of interest. Stroke counts were calculated on the time-activity curves substracting from the maxımum, those counts obtained at the nadir of the curve No background activity substraction was done. The stroke index ratio (SIR) was defined as the ratio of the left stroke counts over the right stroke counts. Ideal ratio should be 1.0 but our experience and data from the literature $^{5.7-101}$ had shown that it varies from 0.8 to 1.7 in a normal population, with a mean value of 12 . We chose 1.2 as a correction factor for the calculation of the regurgitant fraction:

$$
R F(\%)=\frac{\operatorname{SIR}-1 \cdot 2}{\operatorname{SIR}} \times 100
$$

The calculation of a left side regurgitation is obviously made only in the absence of right side regurgitation. A valvular regurgitation was defined as significant in the presence of a regurgitant fraction greater than $20 \%(=\operatorname{SIR}$ of 1.5$)$.

\section{Results}

The regurgitant fraction values calculated at catheterization and by CBPS were compared in patients with and without regurgitation (Table 1).

Patients without any left side regurgitation showed a calculated regurgitant fraction ranging from 9 to $24 \%$ (mean $19.5 \%$ ) by catheterization and from 0 to $30 \%$ (mean $16 \%$ ) by CBPS. Seven of the 8 patients had a regurgitant fraction equal or less than $20 \%$ by CBPS

Patients with left side regurgitation had a regurgitant fraction ranging from $27 \%$ to $71 \%$ (mean $41 \%$ ) by catheterization and from $26 \%$ to $74 \%$ (mean $42 \%$ ) by CBPS. All 41 patients with regurgitation had a regurgitant fraction greater than $20 \%$ by CBPS.

Figure 1 depicts the correlation between the values obtained by the two techniques. The correlation coefficient is good $r=0.82$. CBPS slightly underestimates regurgitation when compared with catheterization: $y=0.93 \times+1.8$.

In patients with pure regurgitation, mitral or aortic. the regurgitant fraction calculated with the two techniques was also compared with angiographic semi-quantitative visual evaluation which assessed the severity of regurgitation by grading it from 1 to 4. (Fig. 2) No correlation was found between this visual estimate and the value calculated by either catheterization or CBPS. 
Table I Population data and regurgitant fraction calculated by catheterization and cardiac blood pool scintigraphy

\begin{tabular}{|c|c|c|c|c|c|c|c|c|}
\hline & \multirow{2}{*}{$\begin{array}{c}\text { Name } \\
\text { VBG }\end{array}$} & \multirow{2}{*}{$\frac{\text { Sex }}{F}$} & \multirow{2}{*}{$\begin{array}{c}\begin{array}{c}\text { Age } \\
\text { (years) }\end{array} \\
60\end{array}$} & \multicolumn{2}{|c|}{$\begin{array}{l}\text { Diagnosis severity } \\
\text { (1-4 degree) }\end{array}$} & \multirow{2}{*}{$\begin{array}{c}\text { RF\% } \\
\text { Cath. } \\
36\end{array}$} & \multirow{2}{*}{$\begin{array}{c}\text { RF\% } \\
\text { CBPS } \\
26\end{array}$} & \multirow{2}{*}{$\begin{array}{l}\begin{array}{c}\text { Associated } \\
\text { disease }\end{array} \\
\text { MS }\end{array}$} \\
\hline 1 & & & & AI 1 & & & & \\
\hline 2 & $\mathbf{N G}$ & $\mathrm{F}$ & 70 & & MI 1 & 35 & 35 & \\
\hline 3 & TM & $\mathrm{F}$ & 69 & AI 1 & MI 2 & 44 & 37 & AS \\
\hline 4 & PA & $\mathbf{M}$ & 65 & AI 2 & & 40 & 36 & $\mathrm{AS}, \mathrm{CAD}(\mathrm{IV})$ \\
\hline 5 & WH & $\mathrm{F}$ & 34 & AI I & & 42 & 39 & MS \\
\hline 6 & PB & $\mathbf{M}$ & 64 & AI 4 & MI I & 52 & 62 & \\
\hline 7 & $\mathrm{BF}$ & $\mathrm{F}$ & 74 & AI 1 & MI 1 & 42 & 31 & AS \\
\hline 8 & MR & $F$ & 49 & Al 3 & MI 1 & 47 & 34 & \\
\hline 9 & DM & $F$ & 57 & AI 3 & & 31 & 30 & \\
\hline 10 & QM & $M$ & 59 & AI 3 & MI 2 & 60 & 72 & CAD (IV) \\
\hline 11 & LM & $\mathbf{M}$ & 32 & AI 2 & & 36 & 26 & \\
\hline 12 & $\mathrm{LA}$ & $\mathbf{M}$ & 54 & AI 3 & & 43 & 34 & \\
\hline 13 & CF & $\mathrm{F}$ & 69 & AI 2 & MI 3 & 67 & 48 & \\
\hline 14 & FR & $\mathbf{M}$ & 51 & Al 3 & & 44 & 55 & \\
\hline 15 & LC & $\mathbf{M}$ & 55 & & MI 3 & 52 & 51 & IHSS \\
\hline 16 & SJ & $\mathrm{F}$ & 65 & AI 1 & MI 2 & 51 & 45 & MS \\
\hline 17 & BJ & $\mathrm{F}$ & 61 & Al 2 & MI 2 & 55 & 56 & \\
\hline 18 & $\mathbf{B P}$ & $\mathbf{M}$ & 63 & AI 2 & & 44 & 40 & AS \\
\hline 19 & HM & $\mathbf{M}$ & 36 & AI I & MI 3 & 58 & 65 & \\
\hline 20 & $\mathrm{CC}$ & $\mathbf{F}$ & 65 & AI 3 & & 55 & 45 & \\
\hline 21 & DJ & $\mathbf{M}$ & 61 & & MI 4 & 53 & 66 & \\
\hline 22 & BG & $\mathbf{F}$ & 69 & Al 1 & & 29 & 28 & AS \\
\hline 23 & $\mathrm{AF}$ & $\mathbf{F}$ & 24 & AI 3 & & 52 & 44 & \\
\hline 24 & $\mathbf{A A}$ & $\mathbf{M}$ & 50 & Al 3 & & 34 & 30 & AS \\
\hline 25 & $\mathrm{DL}$ & $\mathbf{M}$ & 42 & AI 1 & & 27 & 29 & \\
\hline 26 & SM & M & 55 & AI 2 & & 48 & 37 & \\
\hline 27 & SJ & $\mathbf{M}$ & 48 & AI 3 & & 52 & 43 & \\
\hline 28 & PJ & M & 63 & AI I & & 31 & 38 & \\
\hline 29 & RE & $\mathbf{M}$ & 60 & AI 3 & & 41 & 43 & CAD (IV) \\
\hline 30 & FF & $F$ & 37 & & MI 2 & 46 & 62 & IHSS \\
\hline 31 & FJ & $\mathbf{M}$ & 42 & Al 1 & MI I & 31 & 36 & \\
\hline 32 & FM & $\mathbf{F}$ & 51 & & MI 3 & 58 & 48 & \\
\hline 33 & GP & $\mathbf{M}$ & 60 & AI 4 & & 69 & 68 & \\
\hline 34 & Ol & $\mathbf{M}$ & 33 & & MI 3 & 54 & 53 & \\
\hline 35 & $\mathrm{BE}$ & M & 50 & & MI I & 30 & 44 & \\
\hline 36 & $\mathrm{AB}$ & $\mathbf{M}$ & 21 & Al 4 & & 48 & 61 & \\
\hline 37 & PA & $\mathbf{M}$ & 60 & Al 1 & MI 3 & 64 & 74 & \\
\hline 38 & $\mathrm{OM}$ & $M$ & 55 & Al 2 & MI I & 57 & 42 & \\
\hline 39 & GP & $\mathbf{M}$ & 56 & AI 3 & & 46 & 48 & \\
\hline 40 & $\mathrm{HC}$ & $\mathrm{F}$ & 57 & AI 2 & & 34 & 55 & \\
\hline 41 & $R P$ & $\mathbf{M}$ & 61 & AI 3 & & 71 & 57 & \\
\hline 42 & $\mathbf{B L}$ & M & 50 & - & - & 9 & 0 & CAD (2V) \\
\hline 43 & $\mathrm{CL}$ & $M$ & 50 & - & - & 11 & 20 & $\mathrm{HC}$ \\
\hline 44 & QR & $\mathbf{M}$ & 50 & - & - & 24 & 17 & AS \\
\hline 45 & PG & $F$ & 65 & - & - & 24 & 17 & AS \\
\hline 46 & DB & $\mathbf{M}$ & 59 & - & - & 23 & 17 & CAD (2V) \\
\hline 47 & $\mathrm{DB}$ & $F$ & 63 & - & - & 20 & 20 & CAD (2V) \\
\hline 48 & GF & $\mathbf{M}$ & 58 & - & - & 22 & 30 & AS \\
\hline 49 & LJ & $\mathbf{M}$ & 57 & - & - & 23 & 17 & $\mathrm{HC}$ \\
\hline
\end{tabular}

AS, Aortic stenosis; HC, hypertrophic cardiomyopathy; CAD, coronary artery disease, 1 or 2 vessels (V); MS, mitral stenosis; IHSS: idiopathic hypertrophic subaortic stenosis. 


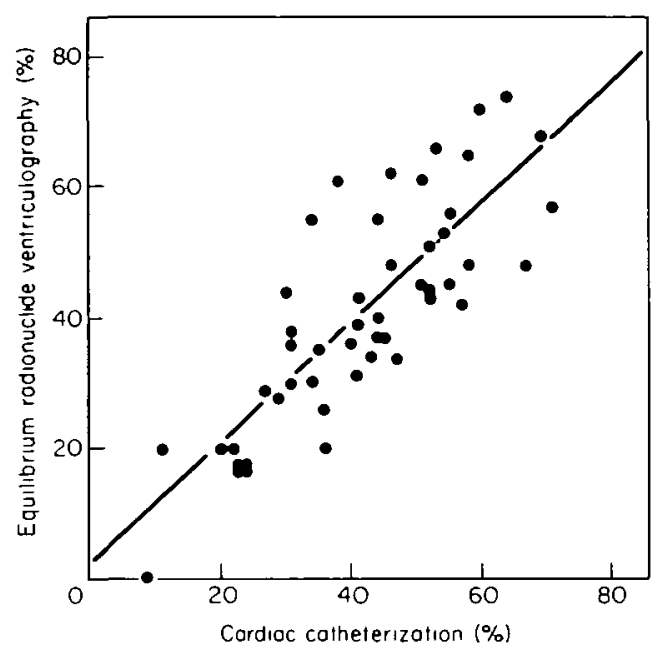

Figure I Comparison of the regurgitant fraction obtained by catheterization and cardiac blood pool scintigraphy in 49 patients. $n=49, y=0.93 x+1 \cdot 8, r=0.82$, SEE $=21$.

\section{Discussion}

Cardiac blood pool scintigraphy has proved to be a useful technique in the evaluation of global and regional ventricular function. Rigo et al. ${ }^{[s]}$ introduced the concept of calculating the regurgitant fraction by companing the stroke counts of the two ventricles. Our results and data from the literature $^{[7-13]}$ contribute to demonstrate the clinical usefulness of this simple principle.

However one should consider some limitations in measuring stroke volume counts obtained by gated equilibrium blood pool scintigraphy in LAO views. It is indeed well known that due to the superposition of atrial and ventricular cavities, drawing a region interest around each ventricle is not always easy. To facilitate the detection of the ventricular contours, especially at the valvular levels, we used functional Images (phase and amplitude) obtained by Fourier analysis.

The correlation we found between regurgitant fraction values by catheterization and CBPS is good $(r=0.82)$ but it is not optimal. Catheterization is conventionally used as 'gold standard' for the calculation of the regurgitant fraction but this technique is prone to errors because of the difficulty to assess enddiastolic and end-systolic volumes and because of the hemodynamic modifications due to the contrast medium injection. This partially explains the limıtations of our comparison. However, we tried to minimize this problem by the following: the angio-
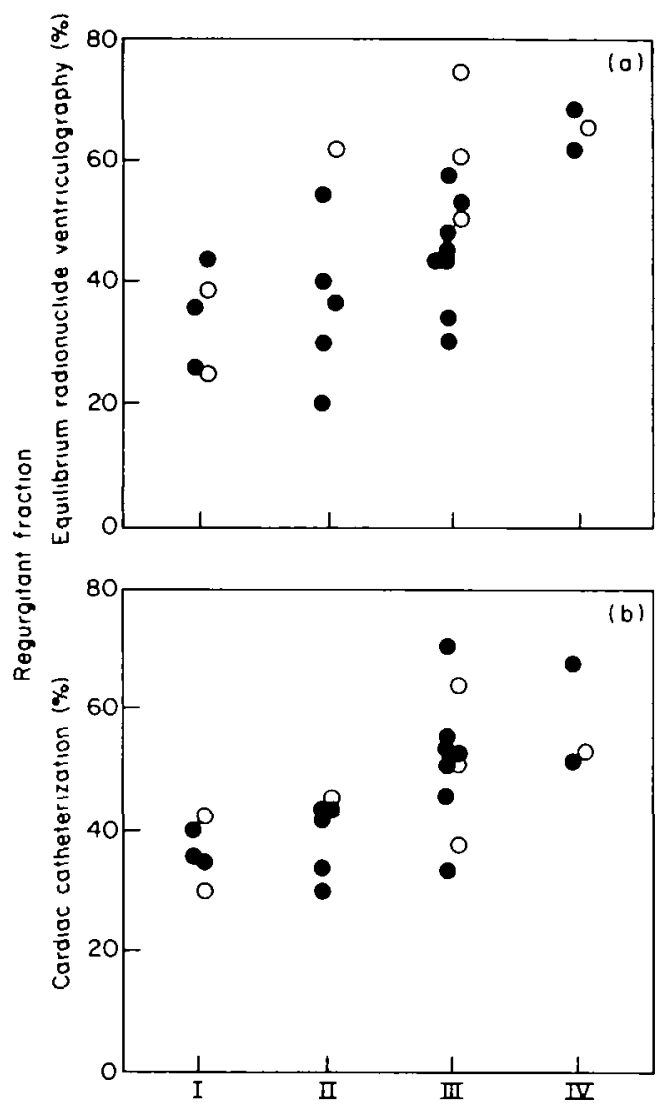

Angiographic semiquantitative visual evaluation

Figure 2 Comparison of the visual evaluation of regurgitation with the quantitative calculation of the regurgitant fraction by cardiac blood pool scintigraphy (top) and catheterization (bottom) in patients with pure aortic $(\bullet)$ or mitral $(O)$ regurgitation.

graphic volumes were determined by two independent observers, care was taken to measure the forward cardiac output using dilution techniques (which we think more accurate than the approximated Fick calculation), only patients with reproducible values were included and cardiac output was determined simultaneously with ventricular angiography.

In our study, the regurgitant fraction values obtained by CBPS were usually slightly inferior to those obtained by catheterization. This is partially related to the introduction of a correction factor (1-2). We think, however, that this correction factor is necessary since, in our experience and according to the literature ${ }^{[5.7-10]}$, the stroke index ratio is usually superior to one (0.8-1.7: mean 1.2) in a normal population. Accordingly, the presence of a 'regurgita- 
tion' with a calculated regurgitant fraction of less than $20 \%(\operatorname{SIR}=1 \cdot 5)$ was considered as not significant. Using these criteria, all 41 patients with regurgitation had a significant regurgitation fraction (26-74\%): sensitivity $100 \%$; while seven out of the eight patients without evidence of regurgitation had a regurgitant fraction within normal limits. In these 8 patients, the regurgitant fraction calculated by catheterization was superior to $0 \%$ and varied from 9 to $24 \%$ with a mean of $20 \%$.

In accordance with other studies ${ }^{[7.14]}$, in our patients with pure aortic or mitral regurgitation we could not find any positive correlation between the visual evaluation of regurgitation and the quantitative measurements of the regurgitant fraction by catheterization or by cardiac blood pool scintigraphy.

In conclusion, we feel that cardiac blood pool scintigraphy, an established method for determination of ventricular dimensions and function, can also be of use in the clinical evaluation of patients with regurgitant lesions. Clinical signs and symptoms are of ten unreliable to establish the severity of a valvular leak, and repeated investigations are, therefore, sometimes necessary to monitor the course of the disease and decide on possible valve replacement. Our data show that cardiac blood pool scintigraphy can represent a safe and non invasive alternative to repeated catheterization in this setting.

We are indebted to Viviane Stuckı, Godefroid Perrot and Daniel Schaller for their valuable assistance in performing the investigations and to Anne Loutan for helping us to prepare the manuscripts.

\section{References}

[1] Hunt D, Baxley WA, Kennedy JW et al. Quantitative evaluation of cineaortography in the assessment of aortic regurgitation. Am J Cardiol 1973; 31: 696-700.
[2] Sellers RD, Levy MS, Amplatz K, Lilleher CW. Left retrograde cardioangiography in acquired cardiac disease. Am J Cardiol 1964; 14. 437-47.

[3] Sandler H, Dodge HT, Hay RE, Rackley CE. Quantıtation of valvular insufficency in man by angiocardiography. Am Heart J 1963; 65: 501-13.

[4] O'Rourke RA, Crawford MH. Timing of valve replacement in patients with chronic aortic regurgitation Circulation 1980; 61: 493-5.

[5] Rigo P, Alderson PO, Robertson RM. Becker LC. Wagner HN Measurement of aortic and mitral regurgitation by gated cardiac blood pool scans. Circulation 1979; 60: 306-11.

[6] Kennedy JW, Reichenbach DD, Baxley WA, Dodge HT. Left ventricular mass: A comparison of angiocardiographic measurements with autopsy weight. Am J Cardiol 1967; 19: 221.

[7] Lam W, Pavel D, Byrom E, Sheikh A, Best D, Rosen $K$. Radionuclide regurgitant index value and limitations. Am J Cardıol 1981; 47: 292-8.

[8] Sorensen SG, O'Rourke RA, Chaudhur TK. Non invasive quantification of valvular regurgitation by gated equilibrium radionuclide angiography Circulation 1980; 61: 1089-98.

[9] Thompson R, Ross I, Elmes R. Quantification of valvular regurgitation by cardiac gated pool imaging. $\mathrm{Br}$ Heart 1981, 46: 629-35.

[10] Bough EW, Gandsman ES, North DL. Shulkman RS. Gated radionuclide angiographic evaluation of valve regurgitation. Am J Cardiol 1980; 46: 423-8.

[11] Konstam MA, Wynne J, Holman BL, Brown EJ, Neill JM, Kozlowski J. Use of equilibrium gated radionuclide ventriculography to quantitate left ventricular output in patients with and without left-sided valvular regurgitation. Circulation 1981; 64: 578-85.

[12] Nicod P, Corbett JR, Forth BG el al. Radionuclide techniques of valvular regurgitant index comparison in patients with normal and depressed ventricular function. J Nucl Med 1982; 23: 763-9.

[13] Klepzig H. Standke R, Nickelsen el al. Combined first pass and equilibrium radionuchde ventriculography and comparison with left ventricular/right ventricular stroke count ratio in mitral and aortic regurgitation. Am J Cardiol 1985; 55: 1048-53.

[14] Croft CH, Lipscomb K, Mathis K el al. Limitations of qualitative angiographic gradıng in aortic or mıtral regurgitation. Am J. Cardiol 1984, 53: 15938 